\title{
THE INFLUENCE OF PAVEMENT-VEHICLE INTERACTION ON HIGHWAY FUEL CONSUMPTION BY FIELD MEASUREMENT
}

\author{
Xin Jiao, Michael Bienvenu \\ Dept of Civil and Environmental Engineering, Florida International University, Miami, United States
}

Submitted 27 March 2015; resubmitted 8 May 2015; accepted 29 July 2015

\begin{abstract}
Field experiments are performed in which Fuel Consumptions (FCs) are measured by operating passenger car over thirteen one-mile roadway sections at two highway speeds in Florida. The sections are composed of 6 flexible pavement sections and seven rigid pavement sections with varied pavement surface conditions and testing temperature. The first objective is to capture the fuel differences between flexible pavement and rigid pavement considering the effect of pavement roughness and pavement temperature. By ANalysis of COVAriance (ANCOVA), results show less fuel is consumed on rigid pavement opposed to flexible pavement by $2.25 \%$ at $93 \mathrm{~km} / \mathrm{h}$ and $2.22 \%$ at $112 \mathrm{~km} / \mathrm{h}$. Fuel differences are found statistically significant at 95\% Confidence Level (C.L.). Fuel savings on rigid pavement exhibits good agreement with authors' Phase I direct comparison field study. Furthermore, fuel data from flexible pavement is applied to calibrate the Highway Development and Management IV (HDM-4) FC model in order to detect and quantify the impact of pavement deflection on FC. Calibrated models are evaluated and validated with experiment data. By results, the deflection-indhuced fuel effect is disclosed by the positive deflection adjustment coefficient generated from the calibration. It is also found that an increase of $0.1 \mathrm{~mm}$ in pavement deflection at $25{ }^{\circ} \mathrm{C}$ (pavement temperature) would increase the FC by $1.53 \%$ at $93 \mathrm{~km} / \mathrm{h}$ and $1.46 \%$ at $112 \mathrm{~km} / \mathrm{h}$. Results demonstrate good agreement with other findings.
\end{abstract}

Keywords: deflection; fuel consumption; highway; road; pavements; model; statistical analysis.

\section{Notations}

ANCOVA - ANalysis of COVAriance;

BMM - Begin Mile Marker;

C.I. - Confidence Interval;

C.L. - Confidence Level;

EMM - End Mile Marker;

FC - Fuel Consumption;

FE - Finite Element;

FWD - Falling Weight Deflectometer;

IRI - International Roughness Index;

MPD - Mean Profile Depths;

MPG - Miles Per Gallon;

PCC - Portland Cement Concrete;

PT - flexible pavement surface layer mid-depth temperature;

QQ plot - Quantile-Quantile plot;

RWID - roadway identification number;

SSE - sum square of differences/errors.

\section{Introduction}

Oil crises, which frequently occurred during the past decades, have been resulting in decreased public spending on road maintenance and rehabilitation (Formby 2014). At the same time, considerable efforts have been made to improve vehicle design in order to enhance vehicle fuel efficiency (IEA 2012). What often gains less attention is the potential improvement can be obtained by optimizing the pavement design and performance. Thus it is important to not only focus on the efficiency of vehicle on the roads, but to the roadway/pavement itself for the fuel economy improvement, safety enhancement and emission reductions. One of the efforts made by researchers can be found such as the studies of Dell'Acqua et al. (2013) and De Luca et al. (2011) who prove that the optimization design of highway alignment consistency would decrease the number of crashes significantly.

Pavement surface condition, described by roughness and texture, has been shown significant effect on vehicle/tire rolling resistance and fuel economy (Zaabar

Corresponding author: Xin Jiao

E-mail: xjiao002@fiu.edu

Copyright @ 2016 Vilnius Gediminas Technical University (VGTU) Press

http://www.tandfonline.com/TRAN 
et al. 2010). Pavement-vehicle interaction, related primarily to pavement stiffness or the deflections under loads, has also been demonstrated measurable effect on fuel efficiency regardless of vehicle type. As early in 1970s, Walter and Conant (1974) has suggested that for a unit-ton wheel load, 30 pounds force is required for moving the wheel with every one inch of tire sinking (into the ground). Lu (2010) concluded with FE analysis that an increase of 24 microns in pavement vertical deflection would yield a $0.02 \mathrm{~L} / 100 \mathrm{~km}$ increases in fuel consuming to overcome pavement resistance for a 5-axle tractor-trailer. The Massachusetts Institute of Technology pavement-vehicle interaction research, with emphasizes on deflection/dissipation-induced mechanistic models, has predicted that stiffer pavement could reduce FC by up to $3 \%$ for the US roadway network (Akbarian et al. 2012).

Preliminary investigations have also been made by authors back to 2013 as the Phase I field test (Jiao, Bienvenu 2014). The Phase I field experiment was designed and tested on two pairs of flexible-rigid sections with repeated measurements (6-8 measures) at $112 \mathrm{~km} / \mathrm{h}$ (70 mph). The length of the sections is $8 \mathrm{~km}$ (5 miles) for I-95 and $11 \mathrm{~km}$ (7 miles) for I-75 and tests were performed at monthly frequency. An average of $2.50 \%$ higher car FC was found on flexible pavement compared to rigid pavement with tests on two pairs of flexible-rigid sections on I-95 and I-75 in Florida. Each pair was composed of either identical or similar pavement surface, traffic and environmental condition. Differences were all shown statistically significant at a 95\% C.L. However, in Phase I, pavement roughness was the unchanging factor with no statistic variation within each pair of section (average of $47 \mathrm{in} / \mathrm{mile}$ for I-95 sections and $54 \mathrm{in} /$ mile for I-75 sections). Ambient temperature was measured during the test, but its effect on FC was not taken into consideration, neither the pavement temperature. Thus, this phase of field test was initiated and designed to complement such imperfection and to recapture the potential effect of pavement characteristics on FC. The main focus of this study is passenger car. More vehicle classes will be included in future studies.

\section{Research Objectives}

This study aims to bring real-life experiment data to detect the impact of pavement type on FC and explore how pavement deflection affect passenger car FC with the local roadway, environment and highway traffic condition.

There are two specific research questions of this study:

- will there be FC differences between flexible pavement and rigid pavement by taking the effect of surface roughness and pavement temperature into consideration?

- how does pavement deflection affect the passenger car FC on flexible pavement considering temperature effect?

\section{Field Experiment}

\subsection{Experiment Design}

Experiments were designed to assess passenger car FC over a series of highway sections in Florida. Sections were selected in length of $1.6 \mathrm{~km}$ (1 mile) and with flat terrain (zero grad, no bridges/overpasses within each section). The selected 6 flexible pavement sections and 7 rigid pavement sections are located within central/south Florida (Table 1). Information such as section milemarkers, pavement structural/material components, roughness (IRI), surface macrotexture (MPD), falling weight deflectometer (FWD) center deflection and its corresponding pavement temperature (only for flexible pavement), were gathered for each test section before the tests. Summary table is shown as Table 1.

\subsection{Test Vehicle}

A 2014 Chevrolet Cruze was used for all tests with the same driver and data collection personnel. The passenger car was equipped with 1.4 liters I-4 Turbo (138 hp) engine and has a curb weight of $1414 \mathrm{~kg}$ (3118 pound) (Fig. 1a). The tire model is Continental ContiProContact $P 225 / 50 R$ with $0.43 \mathrm{~m}$ (17 in) rim diameter and radial construction. Tire pressures remained constant at 0.24 $\mathrm{MPa}$ (35 psi) throughout the tests (Fig. 1b). Air condition, rain-wipers and radio were turned-off during the tests and lights were set to 'Auto.' Gas tank was fully filled before test on each section. Regular gasoline (87) was used throughout the tests.

\subsection{Data Collection}

On-Board Diagnostic (OBD) device made by AutoEnginuity ${ }^{\circledR}$, L.L.C. (http://www.autoenginuity.com) was used to collect the data at speed of 200 microseconds per reading. The instantaneous data collected were mass air flow rate $[\mathrm{lbs} / \mathrm{min}]$ and vehicle speed $[\mathrm{mph}]$. In addition, pavement surface temperatures were measured with an infrared heat gun $\left[{ }^{\circ} \mathrm{F}\right]$; ambient temperature $\left[{ }^{\circ} \mathrm{F}\right]$ and wind speed/direction [mph] were collected using an anemometer.

Each section was driven two consecutive runs in both directions (northbound/eastbound and southbound/westbound) at two constant speeds of $93 \mathrm{~km} / \mathrm{h}$ (58 mph) and $112 \mathrm{~km} / \mathrm{h}(70 \mathrm{mph})$ with cruise control (Fig. 1c). The two speeds selected (58 $\mathrm{mph}$ and $70 \mathrm{mph}$ ) were intended to simulated the lower highway speed and higher traffic speed condition in state of Florida. In phase I studies, tests were performed under $93 \mathrm{~km} / \mathrm{h}$ (58 mph) for trucks and $112 \mathrm{~km} / \mathrm{h}(70 \mathrm{mph})$ for passenger car. Results can be compared with Phase I studies if the same speeds were applied to Phase I tests. Constant speed over the runs was assured by vehicle cruise control function. Data recordings were manually operated by data collection personnel: start recording when passing BMM and stop recording at point of EMM (Fig. 1d). Sample field recording sheet was shown in Fig. 1e. Experiments were not affected by the traffic flow during the tests. No brakes and accelerations were involved during the data recording sections. 
Table 1. Summary of roadway and pavement information

\begin{tabular}{|c|c|c|c|c|c|c|c|c|c|c|}
\hline Section & RWID & County & BMM & EMM & $\begin{array}{c}\text { Pavement } \\
\text { type }\end{array}$ & $\begin{array}{c}{ }^{\mathrm{a}} \text { Top layer } \\
\text { thickness }[\mathrm{mm}]\end{array}$ & $\begin{array}{c}\mathrm{b} \text { Texture } \\
{[\mathrm{mm}]}\end{array}$ & $\begin{array}{c}\mathrm{c} I R I \\
{[\mathrm{~m} / \mathrm{km}]}\end{array}$ & $\begin{array}{c}\mathrm{d}^{\mathrm{d}} D_{0} \\
{[\mathrm{~mm}]}\end{array}$ & $\begin{array}{c}\mathrm{e} D_{0} \text { temperature } \\
{\left[{ }^{\circ} \mathrm{C}\right]}\end{array}$ \\
\hline F1 & I-95 & St. Lucie & 116 & 117 & HMA & 127 & 1.7 & 0.8 & 0.50 & 53 \\
\hline F2 & I-95 & St. Lucie & 122 & 123 & HMA & 127 & 1.6 & 0.8 & 0.52 & 46 \\
\hline F3 & I-95 & St. Johns & 301 & 302 & HMA & 127 & 1.5 & 1.1 & 0.12 & 25 \\
\hline F4 & I-95 & St. Johns & 307 & 308 & HMA & 127 & 1.5 & 1.0 & 0.14 & 24 \\
\hline F5 & I-95 & Martin & 92 & 93 & HMA & 102 & 1.5 & 1.3 & 0.16 & 24 \\
\hline F6 & I-95 & Martin & 93 & 94 & HMA & 102 & 1.5 & 1.4 & 0.16 & 24 \\
\hline R1 & SR600 & Volusia & 8.327 & 9.376 & JPCP & 210 & 0.5 & 1.1 & N/A & N/A \\
\hline R2 & SR600 & Volusia & 4.791 & 5.791 & JPCP & 210 & 0.5 & 1.1 & N/A & N/A \\
\hline R3 & I-95 & Brevard & 197 & 198 & JPCP & 330 & 0.4 & 0.5 & N/A & N/A \\
\hline R4 & I-95 & Brevard & 199 & 200 & JPCP & 330 & 0.4 & 0.6 & N/A & N/A \\
\hline R5 & I-95 & Brevard & 203 & 204 & JPCP & 330 & 0.5 & 0.7 & N/A & N/A \\
\hline R6 & I-75 & Hillsborough & 254.5 & 255.5 & JPCP & 330 & 0.4 & 1.0 & N/A & N/A \\
\hline R7 & I-75 & Hillsborough & 261.5 & 262.5 & JPCP & 330 & 0.4 & 1.0 & N/A & N/A \\
\hline
\end{tabular}

Notes: Values in a, b, c, d, e are the average value calculated from $1.6 \mathrm{~km}$ ( 1 mile) sections; a - pavement top layer thickness, for flexible pavement, the friction course and asphalt concrete layer are considered as top layer together; for rigid section, the top layer is concrete slab; b - macrotextures as the MPD; c - International Roughness Index; $\mathrm{d}$ - FWD test central deflection without temperature adjustment, not available on rigid pavement; e - pavement temperatures measured during FWD tests, not available on rigid pavement.

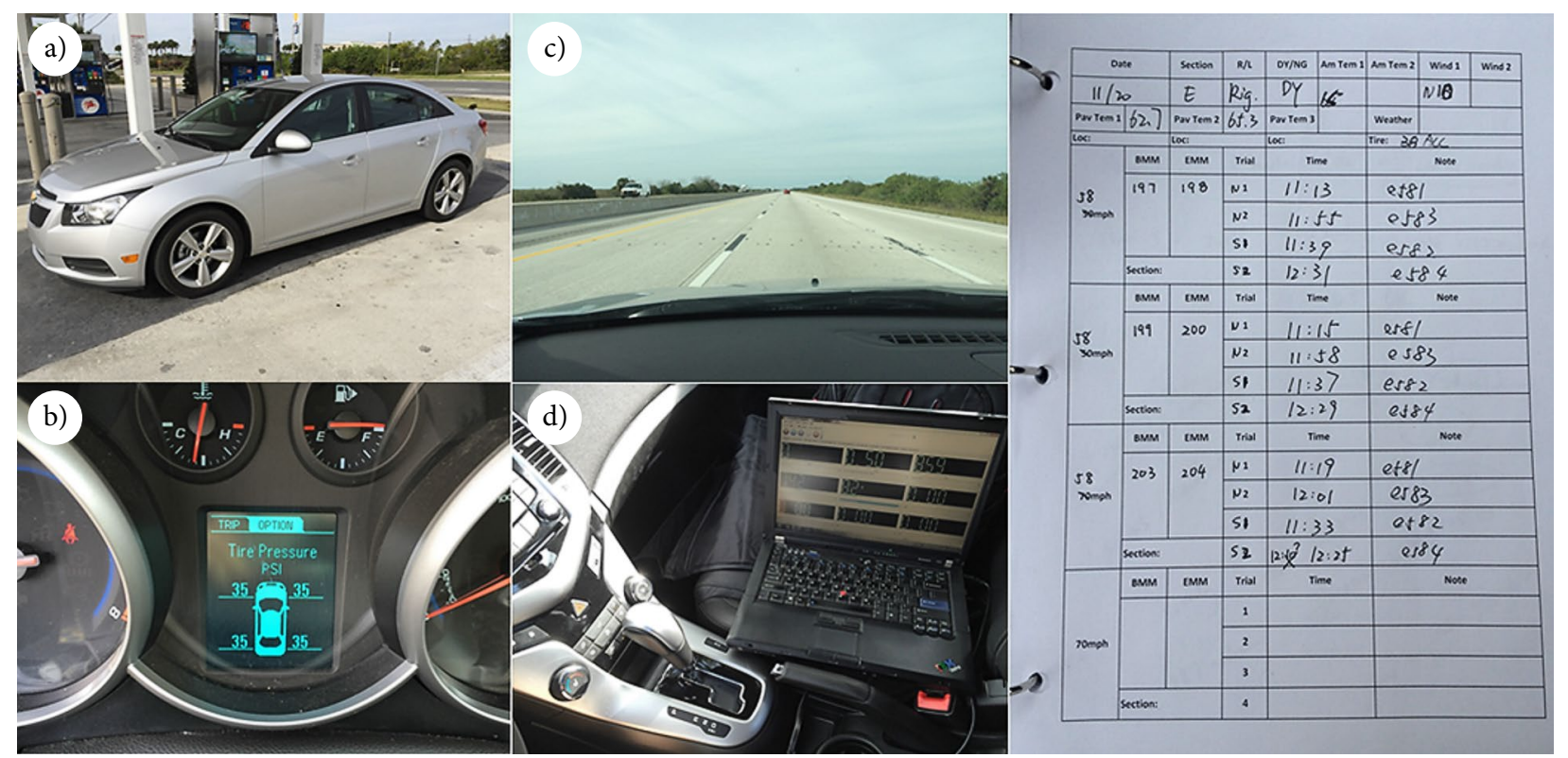

Fig. 1. Photos of field experiments

\subsection{Calculating Fuel Rates}

Instantaneous fuel rates can be determined with Eq. (1) from mass airflow rate and vehicle speed. The formula works very well in modern automobiles since the engine computer spends almost $100 \%$ of its time managing the fuel-air-ratio to 14.7, which it can do very well because of the 'close loop' feedback from $\mathrm{O}_{2}$ sensor(s) (Lightner 2004).

$$
M P G=\frac{14.7 \cdot 6.17 \cdot V S S}{60 \cdot M A F}=1.5 \cdot \frac{V S S}{M A F},
$$

where: $M P G$ is the vehicle fuel rate [miles per gallon]; $V S S$ is vehicle speed [miles per hour]; $M A F$ is the vehicle mass air flow rate [pounds per minute].

\subsection{Data Processing}

A good and robust statistical analysis depends on sufficient data/samples size. If analysis was performed through the 26 1-mile based average FC (13 for each speed), results would become weak and vulnerable. Thus, a 0.1-mile based data points were generated owing to the fact that the IRI and FWD were all available in such scale. Consequently, a number of 260 data points were resulted with 120 data for flexible sections and 140 data for rigid sections.

As mentioned, pavement surface temperatures were measured and recorded during the tests. However, the temperature on pavement surface may not be good 
representatives for the study. Therefore, the surface temperatures were converted to surface layer middle depth temperatures calculated with layer thicknesses and ambient temperatures (Fernando, Liu 2001). For flexible pavement, the open graded friction course and asphalt concrete layer were considered as surface layer together, for rigid pavement, the concrete slab is treated as the surface layer. All units were converted to metric system before analysis and the unit of FC was converted from MPG to Liters per $100 \mathrm{~km}[\mathrm{~L} / 100 \mathrm{~km}]$.

\section{Pavement Type on Fuel Consumption (FC)}

\subsection{Analysis of Covariance (ANCOVA)}

The first step is to statistically test if there is fuel difference between flexible pavement and rigid pavement with consideration of pavement roughness and PT, and how much is the difference if there is any. Different statistic tests were examined and compared. Analysis of covariates was found perfectly match the purpose, as indicated from the definition in Wikipedia (2015) -ANalysis of COVAriance (ANCOVA) evaluates whether population means of a dependent variable (Fuel Consumption FC) are equal across levels of a categorical independent variable (pavement groups, flexible and rigid) often called a treatment, while statistically controlling for the effects of other continuous variables (pavement roughness IRI and PT) and that are not of primary interest, known as covariates or nuisance variables...'.

Intuitively, ANCOVA can be thought as 'adjusting' the dependent variable (FC) by group means of the covariates (IRI and PT), or in this study, detecting the differences in FC between groups by controlling the effect of non-interested variables IRI and PT. The variables used in the test were explained as following:

- Dependent Variable: passenger car FC at $93 \mathrm{~km} / \mathrm{h}$ (58 mph) and $112 \mathrm{~km} / \mathrm{h}(70 \mathrm{mph})[\mathrm{L} / 100 \mathrm{~km}]-$ separate analysis at each speed;

- Independent (Categorical) Variable: pavement groups, flexible pavement group and rigid pavement group, differentiated in pavement surface material, structural components and surface macrotexture;

- Covariates: Pavement roughness IRI [m/km] and pavement surface layer mid-depth temperature $\mathrm{PT}\left[{ }^{\circ} \mathrm{C}\right]$.

Pavement surface texture was not included as one of the covariates given the following explanations:

- texture are available in forms of MPD, which derived from the pavement macrotexture profiles; Studies have shown that megatexture (with longer wavelength) may affect the rolling resistance and fuel efficiency in a negative way, but with little or inconsistent findings on macrotexture;

- the MPDs are at two different levels between flexible sections and rigid sections $(1.55 \mathrm{~mm}$ vs. $0.44 \mathrm{~mm}$ ). This is due to the natural differences in pavement materials themselves.
Texture on PCC pavement is normally supplement treatment and is largely depending on the measuring direction the lase profiler performed. This is most evident on PCC pavements, which have distinct surface striations and/or grooves in the direction of the tinning, dragging, or grinding operation. However, for flexible pavement surfaced with asphalt concrete, it is dominated by mix design and does not change too much from directions. Thus, it is more reasonable/rational to consider the macrotexture as a material dependent parameter, and thus be excluded from the controlling variables (covariates).

\subsection{ANCOVA Results}

Preliminary checks were conducted to ensure that there is no violation of the assumptions of normality (by QQ plot of residuals), linearity (by visualization), homogeneity of variance (by Levene's test) and homogeneity of regression slops (by visualization). Table 2 shows the ANCOVA results at speed of $93 \mathrm{~km} / \mathrm{h}$ and $112 \mathrm{~km} / \mathrm{h}$ separately. From the table, there is a significant effect of the factor 'Group': $F=8.816, p=0.004$ for $93 \mathrm{~km} / \mathrm{h}$ and $F=7.146, p=0.009$ for $112 \mathrm{~km} / \mathrm{h}$. This indicates that after adjusting for IRI and PT, the flexible group and rigid group respond differently in FC at level of 0.05 (or even 0.01). Next, 'how big' or at 'at what levels' the differences are, were evaluated based on the covariates adjusted marginal means. Table 3 shows the pairwise comparison at each speed.

The mean FC of each pavement group was the FC adjusted for the roughness and PT based on their mean values. From Table 3, conclusions may draw that the means differences between two pavement groups (compared to rigid group) are $2.25 \%$ at $93 \mathrm{~km} / \mathrm{h}(58 \mathrm{mph})$ with C.I. of $(0.76 \%, 3.76 \%)$, and $2.22 \%$ at $112 \mathrm{~km} / \mathrm{h}$ (70 mph) with C.I. of $(0.58 \%, 3.85 \%)$.

\subsection{Discussion}

Table 4 summarizes the results from both phases. Although the car used in Phase I test has a weight of nearly $20 \%$ more compared to the car used in this test, both phases exhibited statistical significant fuel savings on rigid pavement (or pavement group) and savings were also found at the same level $(2.50 \%$ vs. $2.25 \%$ and $2.22 \%)$.

There were also some very interesting findings when compare the results of two phases. For the same vehicle class (passenger car) at same speed $(112 \mathrm{~km} / \mathrm{h})$, the higher the vehicle weight (Phase II car of $1414 \mathrm{~kg}$ vs. Phase I car of $1700 \mathrm{~kg}$ ), the higher the fuel differences between rigid pavement and flexible pavement, but only increased in a small magnitude (Phase II of $2.22 \%$ vs. Phase I of $2.50 \%$ ). If compared to the tractor-trailer fuel differences in Phase I at $93 \mathrm{~km} / \mathrm{h}$, (Phase II car of $1414 \mathrm{~kg}$ vs. Phase I tractor-trailer of $34709 \mathrm{~kg}$ (average weight)), the fuel difference increased by $1.79 \%(2.25 \%$ vs. $4.04 \%)$. However, the increases are not linear. 
Table 2. Results of ANCOVA

\begin{tabular}{|c|c|c|c|c|c|}
\hline Source & Type III sum of squares & $d f$ & Mean square & $F$ & Sigma \\
\hline \multicolumn{6}{|c|}{ Dependent Variable: FC_93 km/h $(58 \mathrm{mph})$} \\
\hline Corrected model & 1.237 & 3 & 0.412 & 11.431 & 0.000 \\
\hline Intercept & 163.171 & 1 & 163.171 & 4523.910 & 0.000 \\
\hline IRI_93 & 0.417 & 1 & 0.417 & 11.571 & 0.001 \\
\hline PT_93 & 0.609 & 1 & 0.609 & 16.880 & 0.000 \\
\hline Group & 0.318 & 1 & 0.318 & 8.816 & 0.004 \\
\hline Error & 4.545 & 126 & 0.036 & - & - \\
\hline Total & 3007.898 & 130 & - & - & - \\
\hline Corrected total & 5.782 & 129 & - & - & - \\
\hline \multicolumn{6}{|c|}{ Dependent Variable: FC_112 km/h (70 mph) } \\
\hline Corrected model & 2.983 & 3 & 0.994 & 13.735 & 0.000 \\
\hline Intercept & 290.528 & 1 & 290.528 & 4013.278 & 0.000 \\
\hline IRI_112 & 0.577 & 1 & 0.577 & 7.966 & 0.006 \\
\hline PT_112 & 2.441 & 1 & 2.441 & 33.718 & 0.000 \\
\hline Group & 0.517 & 1 & 0.517 & 7.146 & 0.009 \\
\hline Error & 9.121 & 126 & 0.072 & - & - \\
\hline Total & 5082.357 & 130 & - & - & - \\
\hline Corrected total & 12.104 & 129 & - & - & - \\
\hline
\end{tabular}

Table 3. Pairwise comparisons of analysis covariance

\begin{tabular}{|c|c|c|c|c|c|c|}
\hline \multirow{2}{*}{ Pavement type } & \multirow{2}{*}{$\mathrm{FC}[\mathrm{L} / 100 \mathrm{~km}]$} & \multirow{2}{*}{$\begin{array}{c}\text { Mean difference } \\
\text { (flexible-rigid) [\%] }\end{array}$} & \multirow{2}{*}{ Std. error } & \multirow{2}{*}{ Sigma $^{b}$} & \multicolumn{2}{|c|}{ 95\% C.I. for difference ${ }^{b}[\%]$} \\
\hline & & & & & lower bound & upper bound \\
\hline \multicolumn{7}{|c|}{ Dependent Variable: FC_93 km/h $(58 \mathrm{mph})$} \\
\hline Flexible & $4.863^{\mathrm{a}}$ & 0.107 & 0.036 & 0.004 & 0.036 & 0.179 \\
\hline Rigid & $4.756^{\mathrm{a}}$ & $2.25^{\mathrm{c}}$ & - & - & $0.76^{\mathrm{c}}$ & $3.76^{\mathrm{c}}$ \\
\hline \multicolumn{7}{|c|}{ Dependent Variable: FC_112 km/h $(70 \mathrm{mph})$} \\
\hline Flexible & $6.319^{\mathrm{a}}$ & 0.137 & 0.051 & 0.009 & 0.036 & 0.238 \\
\hline Rigid & $6.182^{\mathrm{a}}$ & $2.22^{\mathrm{c}}$ & - & - & $0.58^{\mathrm{c}}$ & $3.85^{\mathrm{c}}$ \\
\hline
\end{tabular}

Notes: Based on estimated marginal means: a - covariates are evaluated at following values: $I R I \_93=0.944 \mathrm{~m} / \mathrm{km}, P T \_93=17^{\circ} \mathrm{C}$, IRI_112 $=0.944 \mathrm{~m} / \mathrm{km}, P T \_112=17^{\circ} \mathrm{C} ; \mathrm{b}-$ the methodology applied for the pairwise comparisons is Bonferroni approach; $\mathrm{c}-$ percentage differences were calculated as differences compared to rigid FC.

Table 4. Comparisons with Phase I results

\begin{tabular}{|l|c|c|c|}
\hline Tests & Phase II car test & Phase I car test & Phase I truck test \\
\hline Vehicle weight $[\mathrm{kg}]$ & 1414 & 1700 & 34709 \\
\hline Fuel differences at $93 \mathrm{~km} / \mathrm{h}[\%]$ & 2.25 & $\mathrm{n} / \mathrm{a}$ & 4.04 \\
\hline Fuel differences at $112 \mathrm{~km} / \mathrm{h}[\%]$ & 2.22 & 2.50 & $\mathrm{n} / \mathrm{a}$ \\
\hline
\end{tabular}

\section{Pavement Deflection on Fuel Consumption (FC)}

Pavement deflection measurements are the primary means of evaluating pavement structural load transfer capability. Deflections measured were good indications of pavement structural layer stiffness and subgrade resilient modulus and they were widely adopted for layer modulus back-calculation. The FC differences between flexible pavement and rigid pavement are largely owed to the viscoelastic behavior of asphalt material, which leads energy dissipation under deformation caused by vehicle movement. The more 'flexible' (or less stiff) the materials under the tire, the larger the deflection generated, which cause more energy consumed. Then curiosi- ties may be raised that how much or at what level doses the pavement deflection on flexible pavement having influence on vehicle FC. This section focuses on this particular research question.

One of the impact load deflection measurement is FWD test. It has been widely applied in state of Florida. The FWD is designed to impart a load pulse to the pavement surface with deflection sensors mounted radially under the center plate and with offsets at certain increment. This study uses the most simple and direct FWD output - maximum deflection under the center of the load plate - as indicator of the pavement deflection $\left(D_{0}\right)$. Since pavement deflection measured during FWD test is highly dependent on pavement temperature, adjust- 
ment was applied to the center deflections based on the FHWA-RD-98-085 published in 2000 (Lukanen et al. 2000). The calculation involves pavement thickness and ambient temperature as inputs. The average pavement temperature recorded during the FWD tests was used to calculate the temperature adjustment factors, to be differentiated with the temperature measured during the FC test. All $D_{0}$ were adjusted to a reference pavement temperature of $25^{\circ} \mathrm{C}\left(77^{\circ} \mathrm{F}\right)$. Finally, the temperature adjusted FWD center deflection was applied to further analysis.

Multiple linear regressions were first applied to the data with all parameters considered but no significant linear relationship was found between pavement deflection and flexible pavement FC (low $R^{2}$ and high $p$-value). Then the Highway Development and Management IV (HDM-4) FC model was reviewed and attempts were initiated to capture the relationship between pavement deflection and FC through a well calibrated/adjusted prediction model. Thus, flexible pavement fuel data was applied to calibrate the HDM-4 FC models with intent to modify/adjust the pavement related parameters within the models. Rigid pavement data were not applied to the calibration because of the absence of FWD deflection data. Following paragraphs demonstrate the detailed model calibration and validation.

\subsection{Calibration}

\subsubsection{HDM-4 Models}

Rolling resistance, more specifically referred as 'pavement-induced rolling resistance' in this study, is a major component of the 'resistances' the vehicle required to overcome for movement. The rolling resistance term $F_{r}$ in HDM-4 FC model was adopted as Eqs (2-3) (Bennett, Greenwood 2003):

$F_{r}=C R_{2} \cdot \operatorname{FCLIM} \cdot\left(b_{11} \cdot N_{w}+C R_{1} \cdot\left(b_{12} \cdot M+b_{13} \cdot v^{2}\right)\right) ;$

$C R_{2}=K_{c r 2} \cdot\left(a_{0}+a_{1} \cdot T_{d s p}+a_{2} \cdot I R I+a_{3} \cdot D E F\right)$,

where: $F_{r}$ is the vehicle rolling resistance while moving; $C R_{2}$ is rolling resistance surface factor; FCLIM is climate modification factor; $b_{11}, b_{12}$ and $b_{13}$ are rolling resistance tire parameter; $C R_{1}$ is rolling resistance tire factor; $N_{w}$ is the numbers of wheels; $M$ is the vehicle weight in $\mathrm{kg}$; $\mathrm{v}$ is vehicle speed [m/s]; $K_{c r 2}$ is model default calibration factor; $a_{0}$ is the intercept of $C R_{2}$ term; $a_{1}, a_{2}$ and $a_{3}$ are coefficients that modify pavement texture, roughness and deflection; $T_{d s p}$ is texture depth [mm] measured by sand patch method; IRI is international roughness index $[\mathrm{m} / \mathrm{km}] ; D E F$ is Benkelman Beam rebound deflection [mm]. For simplicity, coefficients $a_{0}, a_{1}, a_{2}$ and $a_{3}$ will be named as model intercept, texture coefficient, roughness coefficient and deflection coefficient.

\subsubsection{Model Deficiencies}

However, some of the pavement related parameters (texture/deflection) in this model have been out of age, such as texture are currently collected by laser profilometer instead of with sand patch method in most of the states in US. Benkelman Beam rebound deflection measurement has also been discarded and substituted by FWD test. Moreover, the default value that the HDM-4 manual adopts for the deflection coefficient (a3) is zero for vehicle with weight less than $2500 \mathrm{~kg}$ (5512 lbs). But researchers (Walter, Conant 1974; Lu 2010; Akbarian et al. 2012; Louhghalam et al. 2014a, 2014b) have shown increasing evidence on the potential influence of pavement deflection on FC with all levels of vehicle classes. Thus, queries were raised to investigate whether deflectioninduced FC effect should be neglected in mechanistic FC models.

\subsubsection{Data Adjustment}

Before the calibration performed, data adjustments were made:

- all units were converted to metric system and the unit of fuel rates were transformed to milliliters per second $(\mathrm{mL} / \mathrm{s})$ to be consistent with HDM-4 output;

- the default Benkelman Beam rebound deflections were substituted by the temperature adjusted FWD center deflections;

- pavement textures were converted to $T_{d s p}$ (by sand patch method) from MPD, with Eq. (4) suggested by Bennett (1999):

$T_{d s p}=1.02 \cdot M P D+0.28$;

- total of 120 data were randomly divided into two groups as 90 training data and 30 testing data. The 90 training data were applied to model calibration and the remaining 30 testing data were used to validate the calibrated model. The method used here is the so-called 'hold-out validation'.

\subsubsection{Model Calibration}

The coefficients that were targeted to calibrated are: the two default model calibration coefficients, $K_{c r 2}$ (which modifies rolling resistance) and $K_{\text {pea }}$ (which modifies engine/accessory powers) (Bennett, Paterson 2000), and the four rolling resistance coefficients: model intercept $a_{0}$, texture coefficient $a_{1}$, roughness coefficient $a_{2}$, and deflection coefficient $a_{3}$, which composed of rolling resistance pavement surface factor $C R_{2}-$ Eq. (3). Least Squares Method was used with the Excel Solver Add-in. The approach is to minimize the SSE between predicted FC and measured FC. Three models were generated during the calibration:

- Model A: Non-calibrated model with default $K_{\text {pear }}$, $K_{c r 2}$ and $a_{0}, a_{1}, a_{2}$ and $a_{3}$;

- Model B: $K_{\text {pea }}$ and $K_{c r 2}$ calibrated, default $a_{0}, a_{1}$, $a_{2}$, and $a_{3}$;

- Model C: $a_{0}, a_{1}, a_{2}$ and $a_{3}$ calibrated and $K_{p e a} / K_{c r 2}$ adopted from Model $\mathrm{B}$.

\subsubsection{Calibration Results}

Table 5 summarizes the calibration results. From the table, we found that there is little or no change for texture coefficients $a_{1}$ and roughness coefficient $a_{2}$, which modifies pavement texture and roughness respectively. 
Table 5. Calibration results

\begin{tabular}{|c|c|c|c|c|c|c|c|}
\hline Model & $K_{\text {pea }}$ & $K_{c r 2}$ & $a_{0}$ & $a_{1}$ & $a_{2}$ & $a_{3}$ & SSE \\
\hline $\mathrm{A}$ & 1.000 & 1.000 & 0.500 & 0.020 & 0.100 & 0.000 & 64.780 \\
\hline $\mathrm{B}$ & 1.901 & 0.491 & 0.500 & 0.020 & 0.100 & 0.000 & 6.930 \\
\hline $\mathrm{C}$ & 1.901 & 0.491 & 0.000 & 0.020 & 0.122 & 0.310 & 0.250 \\
\hline
\end{tabular}

The model intercept $a_{0}$ was decreased from 0.500 to 0.000 . The deflection coefficient $a_{3}$, which adjusts pavement deflection, was increased from 0.000 to 0.310 . Values of SSE were also presented in last column.

\subsection{Validation}

When assessing the quality of a model, being able to accurately measure the prediction error, is of key importance. In order to test the accuracy and good of fitness of the calibrated model, three approaches were applied for evaluation of calibrated model, as described below.

\subsubsection{Validation $\mathrm{I}-R^{2}$ and adjusted $R^{2}$}

Coefficient of determination, known as $R^{2}$, is by far the most widely used and reported measure of error and goodness of fit. Coefficient of determination of Model C was calculated based on SSE between the measurement and model prediction. Resulted $R^{2}$ and adjusted $R^{2}$ are 92.5\% and $92.2 \%$ respectively. The high $R^{2}$ and adjusted $R^{2}$ indicate a good fit of observed FC to the calibrated model at a first glance.

\subsubsection{Validation II - Residuals Plots}

Residuals (errors) were then calculated and evaluated graphically in order to see the changes of bias and homogeneity from Model A to Model C. With residuals plots, one can visually assess whether the observed error is consistent with the stochastic error. It is a general accepted visualization approach to evaluate how well the model fits the data.

In this study, two types of plots were generated with standardized residuals and absolute non-standardized residuals. Plotting standardized residuals was intended to detect the trend of data pattern before and after calibration. Theoretically, the more close the data pattern gathering around zero, the better the model fitness. By plotting similar plot with absolute non-standardized residuals, the trend of model biases can be examined.

As shown in Fig. $2 \mathrm{a}-\mathrm{c}$, the standardized residuals vs. fitted values for Models A, B and C. A smooth curve (polynomial with order of 6) was added into each data patterns in order to see the data trend more obviously. Plots on Fig. $2 \mathrm{a}-\mathrm{c}$ evaluate the model fitness based on the tendency of the data pattern. The better the model fit the data, the more closely the trend-curve gathers around the horizontal zero line. Such tendency can be detected from Model A to Model C, which indicates that the model fitness increased from non-calibrated model to calibrated model.

Plot in Fig. 2d replaced the standardized residuals with the absolute value of non-standardized residuals and combined all three models in one plot. By checking the absolute residuals, one can visualize if there is a
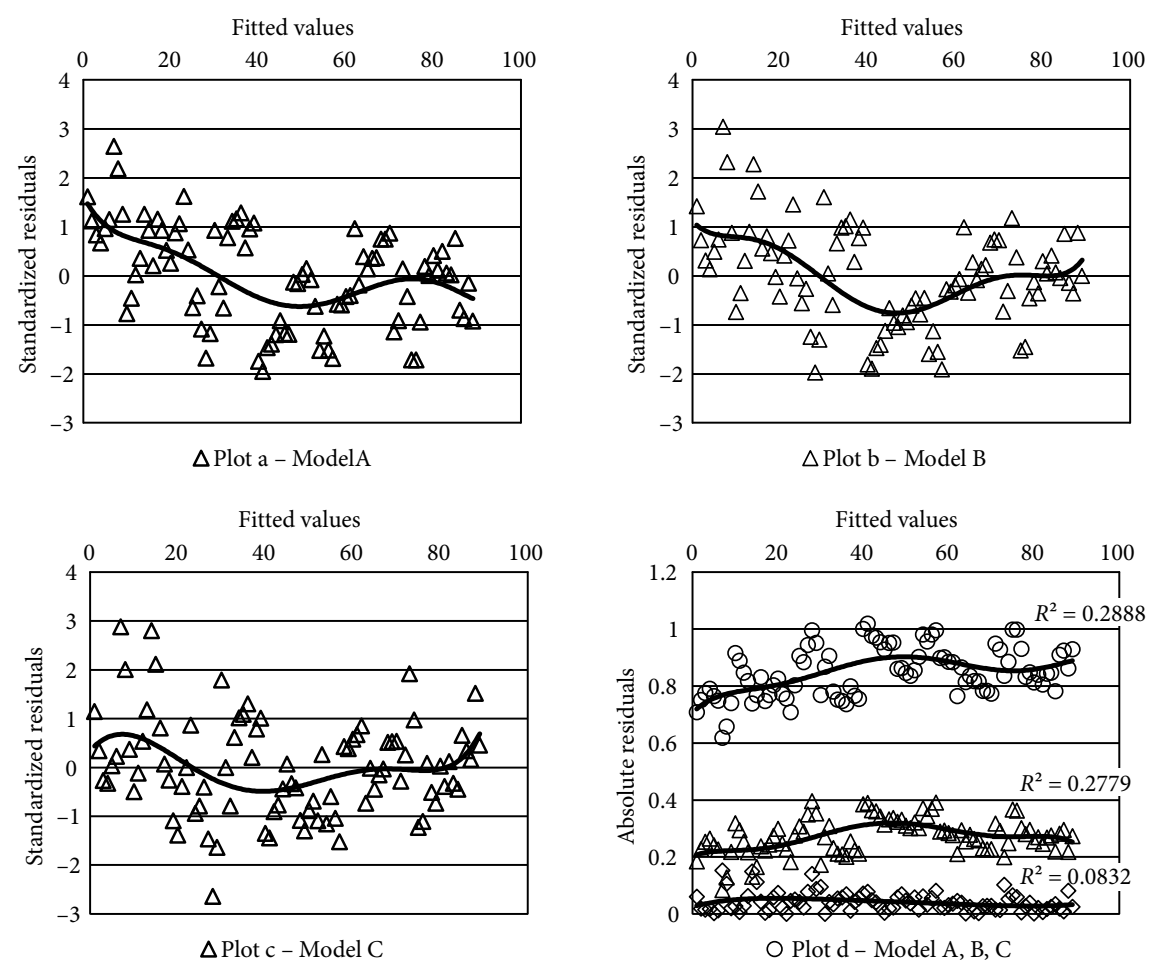

Fig. 2. Residuals plots 
trend in direction of fitted values. The more obvious the tendency, the higher the bias the model possesses. In plot of Fig. 2d, from Model A to Model C (from up to down), the gradually flattened trend-curves clearly indicates that bias was decreased from non-calibrated model to fully calibrated model. The reduced data spreads also exhibits the enhanced data variance homogeneity.

\subsubsection{Validation III - Hold-out Validation}

Both the previous techniques are based on parametric and theoretical assumptions. Holdout validation was applied for the final validation. The advantage of holdout validation is the application of real data to estimate the true prediction error instead of relying on assumptions.

Twenty-five percent of total data (30 data) were applied to evaluate the model. Statistic summary (by paired $t$-test) is shown in Table 6. Results show that the testing data exhibits lower level of SSE compared to training data ( 0.04 vs. 0.25$)$ and there is no statistically significant difference at $95 \%$ C.L. between the model predictions and real measurements $(p$-value $=0.100)$.

Table 6. Results of hold-out validation

\begin{tabular}{|c|c|c|c|c|}
\hline $\begin{array}{c}\text { SSE of } \\
\text { training }\end{array}$ & $\begin{array}{c}\text { SSE of } \\
\text { testing }\end{array}$ & $\begin{array}{c}\text { Mean of } \\
\text { prediction }\end{array}$ & $\begin{array}{c}\text { Mean of } \\
\text { measurement }\end{array}$ & $p$-value \\
\hline $0.25 \mathrm{~mL} / \mathrm{s}$ & $0.04 \mathrm{~mL} / \mathrm{s}$ & $1.463 \mathrm{~mL} / \mathrm{s}$ & $1.475 \mathrm{~mL} / \mathrm{s}$ & 0.100 \\
\hline
\end{tabular}

\subsection{Prediction}

The sensitivity of pavement deflection on FC was evaluated based on the calibrated Model C. For flexible pavement studied in this experiment, the temperature adjusted center deflection (referenced to $25^{\circ} \mathrm{C}\left(77^{\circ} \mathrm{F}\right)$ varies between $0.106 \mathrm{~mm}$ ( $4.2 \mathrm{mils})$ and $0.403 \mathrm{~mm}$ (15.9 mils). With other variables assigned with fixed values, Fig. 3 shows the percentage changes in $\mathrm{FC}[\mathrm{mL} / \mathrm{s}]$ (relative to the FC at $0.106 \mathrm{~mm}$ ) with changes of pavement deflections [mm] from 0.106 to $0.403 \mathrm{~mm}$. The following values were assigned to the non-interested variables (opposed to pavement deflection):

- IRI = $1 \mathrm{~m} / \mathrm{km}$ (63 in/mile);

- texture $=1.83 \mathrm{~mm}$ of $T_{d s p}=1.52 \mathrm{~mm}$ of MPD (0.06 in);

- $P T=25^{\circ} \mathrm{C}\left(77^{\circ} \mathrm{F}\right)$, which indicates no temperature adjustment for center deflection.

As shown in Fig. 4, the FC increases slightly 'faster' at lower highway $(93 \mathrm{~km} / \mathrm{h})$ speed than higher highway speed $(112 \mathrm{~km} / \mathrm{h})$. Specifically, a $0.1 \mathrm{~mm}$ increase of $D_{0}$ at $25^{\circ} \mathrm{C}\left(77^{\circ} \mathrm{F}\right)$ would cause an increase of fuel by $1.53 \%$ at $93 \mathrm{~km} / \mathrm{h}(58 \mathrm{mph})$, and $1.46 \%$ at $112 \mathrm{~km} / \mathrm{h}(70 \mathrm{mph})$.

Results were compared to studies performed by $\mathrm{Lu}$ (2010), who claims that an increase of 24 microns in vertical deflection yields a corresponding $0.02 \mathrm{~L} / 100 \mathrm{~km}$

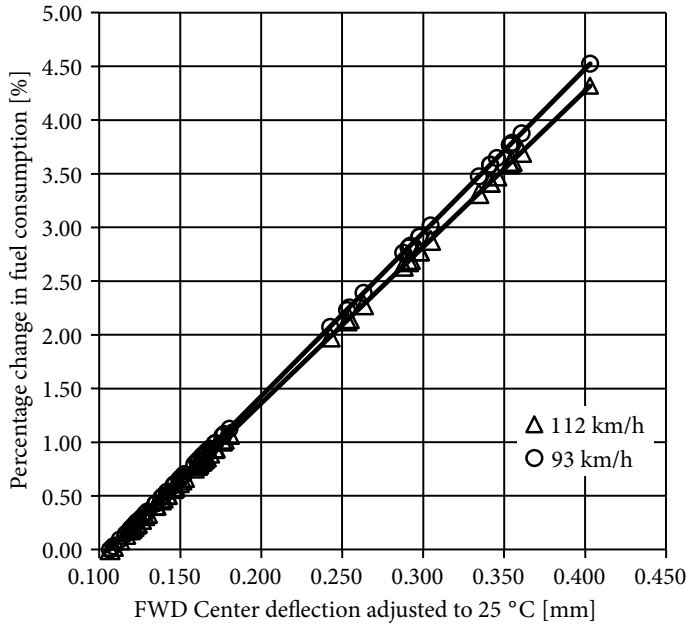

Fig. 3. Relationship between pavement deflection and changes in FC

increase in FC to overcome pavement resistance for a 5-axle tractor-trailer. Transform the units to this study, Table 7 summarizes the comparisons. Generally, results show good agreement at both speeds, despite the different vehicle and study methodology were used.

Following conclusions shall be drawn based on the analysis above:

- the resulted deflection coefficient $a_{3}$ after calibration, which equal to 0.310 , indicates that by model calibration/adjustment, the effect of pavement deflection on FC was disclosed and resulted as the largest coefficients for $\mathrm{CR}_{2}$;

- the calibrated texture coefficients $a_{1}$ and roughness coefficient $a_{2}$ (with little or no change) indicates good agreement with recommended HDM4 coefficients;

- the calibrated model exhibited enhanced measure of fit and reduced bias compared to non-calibrated model.

- the calibrated model is able to predict reality.

With other parameters remain constant, passenger car FC increases with the increase of pavement deflection on flexible pavement.

\section{Concluding Remarks}

This study recaptured the fuel differences between flexible pavement and rigid pavement while controlling other fuel-related factors through the analysis of covariates. Responds to the first research question raised at beginning of this paper: by experiment, rigid pavement again shows less FC and better fuel efficiency compared to flexible pavement. Results exhibit good agreement with Phase I field study, both at level from 2 to $3 \%$. Results

Table 7. Comparison with Lu's study

\begin{tabular}{|c|c|c|c|c|}
\hline \multirow{2}{*}{ Studies } & \multicolumn{2}{|c|}{ Increase of FC $[\mathrm{mL} / \mathrm{s}]$ with $0.1 \mathrm{~mm}$ increase of $D_{0}$} & \multirow{2}{*}{ Vehicle used } & \multirow{2}{*}{ Study method } \\
\cline { 2 - 3 } & at $93 \mathrm{~km} / \mathrm{h}$ & at $112 \mathrm{~km} / \mathrm{h}$ & & \\
\hline Lu (2010) & 0.022 & 0.026 & tractor-trailer & FE modeling \\
\hline This study & 0.019 & 0.027 & passenger car & field tests \\
\hline
\end{tabular}


also reveal that the fuel differences increases with the increase of vehicle weight, but not in a linear manner. It is worth to mention that both phases focus on fuel efficiency on highway driving condition instead of city/ rural condition.

The HDM-4 FC model was calibrated and validated with the flexible pavement data at second part of the study. The objective of the calibration is to capture and quantify the deflection-induced fuel effect by adjusting pavement-related coefficients in HDM-4 FC model. Pavement deflection was represented by FWD test center deflection with temperature adjustment. Groups of coefficients were obtained and the calibrated model was evaluated by three validation methods. Results demonstrate well-calibrated model with reasonable ability to predict reality. Effect of pavement deflection on FC was also revealed by the non-zero deflection coefficient $a_{3}$ after calibration. The positive value of deflection coefficient $a_{3}$ also indicates that the deflection affect the FC in a positive manner (the more the deflection, the higher the fuel consumed).

The impact of pavement deflection on fuel consuming was further investigated by fixing roughness, texture and pavement temperature in the final calibrated model. A sensitivity of $1.53 \%$ increase of FC at $93 \mathrm{~km} / \mathrm{h}$ (58 mph) and $1.46 \%$ at $112 \mathrm{~km} / \mathrm{h}(70 \mathrm{mph})$ was found with every $0.1 \mathrm{~mm}$ 's increase of pavement deflection at $25^{\circ} \mathrm{C}\left(77^{\circ} \mathrm{F}\right)$ (pavement temperature). Despite the study, methodologies and vehicle used compared to Lu's et al. (2010) research; good agreement was recognized with the same level of influences.

Flexible pavement accounts for $95 \%$ of the interstates and multi-lanes roadways in Florida. The viscoelastic behavior of asphalt material leads energy dissipation when loads create local deformation under the tires. The more 'flexible' (or less stiff) the materials under the tire, the larger the deflection generated, which cause more energy consumed. The impact may be small for a single vehicle; the accumulated effect for the traffic state widely or nation widely would be a major contributor in the lifecycle footprint of pavements. A comprehensive fuel efficiency policy should not only focus on the vehicle technology, but the roads themselves. Pavement selection can play an essential role in the context of fuel efficiency policy. This study is intended to help policymakers and stakeholders to better recognize a dual mandate to the fuel reduction objectives - one on vehicle technology and another on pavement selection.

\section{References}

Akbarian, M.; Moeini-Ardakani, S.; Ulm, F.-J.; Nazzal, M. 2012. Mechanistic approach to pavement-vehicle interaction and its impact on life-cycle assessment, Transportation Research Record: Journal of the Transportation Research Board 2306: 171-179. http://doi.org/10.3141/2306-20

Bennett, C. R. 1999. Calibration of HDM Speed Prediction Model to Thailand. Final Report DES/99/2. Highway and Traffic Consultants Ltd., UK. 119 p.

Bennett, C. R.; Greenwood, I. D. 2003. HDM-4: Highway Development \& Management. Volume 7: Modelling Road User and Environmental Effects in HDM-4. Version 3.0. Interna- tional Study of Highway Development and Management Tools (ISOHDM), World Road Association (PIARC). $414 \mathrm{p}$.

Bennett, C. R.; Paterson, W. D. O. 2000. HDM-4: Highway Development \& Management. Volume 5: A Guide to Calibration and Adaptation. Version 1.0. International Study of Highway Development and Management Tools (ISOHDM), World Road Association (PIARC). 229 p.

Dell'Acqua, G.; Busiello, M.; Russo, F. 2013 Safety data analysis to evaluate highway alignment consistency, Transportation Research Record: Journal of the Transportation Research Board 2349: 121-128. http://doi.org/10.3141/2349-14

De Luca, M.; Mauro, R.; Russo, F.; Dell'Acqua, G. 2011. Beforeafter freeway accident analysis using cluster algorithms, Procedia - Social and Behavioral Sciences 20: 723-731. http://doi.org/10.1016/j.sbspro.2011.08.080

Fernando, E. G.; Liu, W. 2001. User's Guide for the Modulus Temperature Correction Program (MTCP). Report FHWA/ TX-01/1863-2, Texas Department of Transportation, Austin, Texas, US. 56 p.

Formby, B. 2014. Falling oil prices could deepen Texas road funding woes, The Dallas Morning News: 28 December 2014. Available from Internet: http://www.dallasnews.com/ news/transportation/20141228-falling-gas-prices-coulddeepen-states-transportation-funding-woes.ece

IEA. 2012. Improving the Fuel Economy of Road Vehicles: a Policy Package. International Energy Agency (IEA), Paris, France. 86 p. Available from Internet: https://www.iea.org/ publications/freepublications/publication/policy-pathwaysimproving-the-fuel-economy-of-road-vehicles---a-policypackage.html

Jiao, X.; Bienvenu, M. 2015. Field measurement and calibration of HDM-4 fuel consumption model on interstate highway in Florida, International Journal of Transportation Science and Technology 4(1): 29-46.

http://doi.org/10.1260/2046-0430.4.1.29

Lightner, B. D. 2004. AVR-based fuel consumption gauge, Circuit Cellar: the Magazine for Computer Applications 183: 59-67.

Louhghalam, A.; Akbarian, M.; Ulm, F. 2014a. Flügge’s Conjecture: dissipation- versus deflection-induced pavement-vehicle interactions, Journal of Engineering Mechanics 140(8). http://dx.doi.org/10.1061/(ASCE)EM.1943-7889.0000754

Louhghalam, A.; Akbarian, M.; Ulm, F.-J. 2014b. Pavement infrastructures footprint: the impact of pavement properties on vehicle fuel consumption, in Computational Modelling of Concrete Structures: Proceedings of EURO-C 2014, 24-27 March 2014, St. Anton am Arlberg, Austria, 2: 1051-1058.

Lu, T., Thom, N.; Parry, T. 2010. Numerical simulation of the influence of pavement stiffness on energy dissipation, in Computing in Civil and Building Engineering: Proceedings of the International Conference, 30 June - 2 July, Nottingham, UK, 483-484.

Lukanen, E.; Stubstad, R.; Briggs, R. 2000. Temperature Predictions and Adjustment Factors for Asphalt Pavement. Report FHWA-RD-98-085. Federal Highway Administration, US Department of Transportation. $79 \mathrm{p}$.

Walter, J. D.; Conant, F. S. 1974. Energy losses in tires, Tire Science and Technology 2(4): 235-260. http://doi.org/10.2346/1.2167188

Wikipedia. 2015. Analysis of Covariance. Available from Internet: http://en.wikipedia.org/wiki/Analysis_of_covariance

Zaabar, I. 2010. Effect of Pavement Condition on Vehicle Operating Costs Including Fuel Consumption, Vehicle Durability and Damage to Transported Goods: PhD Dissertation. Michigan State University, East Lansing, Michigan, US. 307 p. 